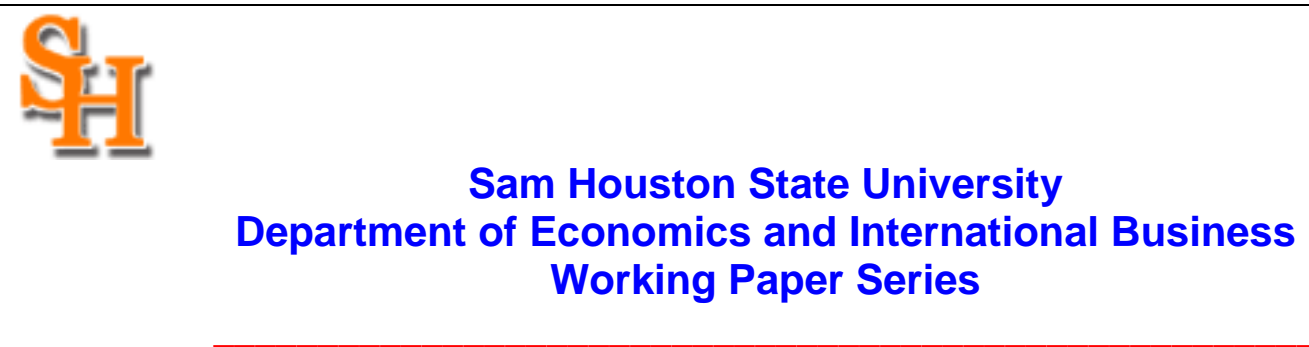

Media Substitution in Advertising: A Spirited Case Study

\author{
Mark W. Frank \\ SHSU Economics \& Intl. Business Working Paper No. SHSU_ECO_WP06-06 \\ September 2006
}

\begin{abstract}
:
This paper uses an unusually rich sample of liquor brands in the U.S. over the period 1994 to 2004 to test substitutability of advertising media. The liquor industry in the U.S. has experienced a substantial increase in case sales and advertising expenditures since the mid-1990s, raising numerous public policy concerns. Moreover, the mix of advertising media used by liquor brands also changed substantially following the industry's decision in 1996 to begin using radio and television media. We find that the advertising media used by liquor firms are highly substitutable, meaning that partial media bans, such as a ban on television advertising, would prove ineffective in reducing liquor case sales.
\end{abstract}

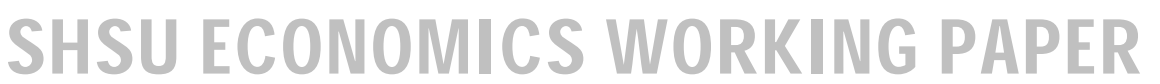




\title{
Media Substitution in Advertising: A Spirited Case Study
}

\begin{abstract}
This paper uses an unusually rich sample of liquor brands in the U.S. over the period 1994 to 2004 to test the substitutability of advertising media. The liquor industry in the U.S. has experienced a substantial increase in case sales and advertising expenditures since the mid-1990s, raising numerous public policy concerns. Moreover, the mix of advertising media used by liquor brands also changed substantially following the industry's decision in 1996 to begin using radio and television media. We find that the advertising media used by liquor firms are highly substitutable, meaning that partial media bans, such as a ban on television advertising, would prove ineffective in reducing liquor case sales.
\end{abstract}

Keywords: Liquor; Advertising; Media Substitution; Translog Cost Function JEL Classifications: L13, L66, M37

\section{Introduction}

Alcoholic beverages in the United States have a unique and controversial public policy history. Certainly no other substance has been the direct target of two constitutional amendments (the Eighteenth and Twenty-first). While moderate use of alcohol is harmless for many, large numbers of Americans suffer from serious alcohol and alcohol related problems. ${ }^{1}$ The National Institute of Alcohol Abuse and Alcoholism (NIAAA) reports that nearly 14 million Americans abuse alcohol or are alcoholics (NIAAA, 2001). Moreover, the National Highway Traffic Safety Administration reports that of the 42,636 traffic fatalities in 2004, 16,694 (or 39\%) were alcohol-related (NHTSA, 2005). Long-term health problems resulting from heavy alcohol use are well known. More than 2 million Americans, for example, suffer from alcohol-related liver disease (NIAAA, 2002). The 
National Institute of Health estimates that alcohol-related problems cost society approximately $\$ 185$ billion per year (NIAAA, 2001).

Until the mid-1990s, liquor sales in the U.S. had been waning for a quarter century. ${ }^{2}$ As Figure 1 shows, nine-liter case sales of liquor in the U.S. fell from 190.9 thousand in 1980, to a low of 137.3 thousand in 1995. Moreover, liquor's share of the alcoholic beverage industry fell from $44 \%$ in 1970, to 29\% in 1995 (Hemphill, 2002). The industry's outlook in 1995 was bleak. Jobson's Liquor Handbook (1995) stated frankly, "The outlook is grim, with distilled spirits projected to decline at a rate of $2.1 \%$ over the next five years. By the end of the century, total distilled spirits consumption is estimated to drop an additional 14 million cases" (p. 6). Surprisingly, liquor sales began to increase in 1996, and have continued to increase each year since. By the year 2000, liquor sales reached 148.7 thousand nine-liter cases. By 2004, case sales totaled 165.7 thousand, a $20.7 \%$ increase from the 1995 low.

[Figure 1 about here]

The long-running downward trend in liquor advertising also came to a halt in the mid-1990s (see Figure 1), culminating in the 1996 removal of advertising restrictions that stood for over a halfcentury. In December of 1933, ten months after ratification of the Twenty-First Amendment, liquor firms voluntarily agreed to not advertise on radio. ${ }^{3}$ The agreement was extended in 1948 to include the new medium of television. In June of 1996, however, Seagram broke with the longstanding agreement by airing a commercial for its brand Crown Royal on a local NBC station in Texas (in Figure 1, the vertical reference line denotes the date of this decision by Seagram). ${ }^{4}$ Despite a large public outcry over the airing, the rest of the liquor industry followed suit by formally agreeing to lift its ban on radio and television advertising in November of 1996. The decision was agreed upon unanimously through the Distilled Spirits Council of the United States (DISCUS), the liquor industry's national trade organization and lobbying group. 
Both decisions generated widespread public criticism. President Clinton, for example, publicly derided the actions of liquor firms on several occasions. ${ }^{5}$ Representative Joseph Kennedy even introduced legislation to turn the voluntary ban into law. ${ }^{6}$ Despite these efforts, industry expenditures on radio and television advertising increased rapidly in the years after 1996. Total radio advertising expenditures increased from \$3.2 million in 1996, to \$14.3 million in 2004 (in constant 2004 dollars), an increase of nearly 350\%. Likewise, television advertising expenditures increased almost ten-fold, from \$0.7 million in 1996, to \$68.1 million in 2004.

Currently, the only notable advertising venue remaining unemployed by liquor firms is network television advertising, though even this barrier has been crossed in recent years. In December of 2001 the National Broadcasting Company signed a contract to air liquor ads by the industry leader, Diageo. ${ }^{7}$ Unlike the two public outcries of 1996, the ensuing outcry in this instance succeeded in forcing a reversal. In March of 2002, NBC ended its advertising relationship with Diageo (see Hemphill 2002).

This paper is the first to examine liquor advertising since the advertising upturn of the mid-1990s. Prior advertising research has tended to focus on alcohol in general (see Nelson 2003, Saffer and Dave 2002, Nelson and Young 2001, and Saffer 1997), or more narrowly, on the beer industry (see Seldon, Jewell, and O'Brien 2000, and Lee and Tremblay 1992). ${ }^{8}$ Within the former, one area of concern has been the efficacy of advertising bans in reducing alcohol consumption. Saffer and Dave (2002), using a cross-national panel, find that advertising bans decrease total alcohol consumption, though this result appears sensitive to the model specification. ${ }^{9}$ Nelson and Young (2001) and Nelson (2003), by contrast, use cross-state panels to show that total alcohol consumption is largely unaffected by bans and other forms of advertising restrictions.

Other earlier empirical work evaluates the effectiveness of alcohol advertising bans in reducing traffic fatalities. Saffer (1997) finds that a ban on broadcast alcohol advertising (television, radio, and outdoor billboards) would reduce traffic fatalities in the U.S. by as much as 5,000 to 10,000 per 
year. Saffer (1991) similarly finds that a broadcast ban on beer and wine advertising would reduce fatalities in the U.S. by 10,000 per year. These projections assume no media substitution, however. If firms responded to a partial ban on broadcast media by increasing their use of non-broadcast media, fatality reductions would likely be diminished. ${ }^{10}$

There is also a large and growing literature examining the impact of beer advertising on the behavior of beer firms. Most notably, Seldon, Jewell, and O’Brien (2000) utilize a translog cost analysis to find a high degree of substitutability between the print, television, and radio advertising of beer firms. As a result, they argue that partial media bans would have little to no effect on overall beer consumption. Separately, Lee and Tremblay (1992) find that advertising of beer firms has little effect on total market demand. Nelson (2005) provides a useful survey of this literature.

For several reasons, however, beer firms are poor analytical substitutes for liquor firms. As noted above, after prohibition liquor firms refrained from using television or radio media until the year 1996. Tremblay and Tremblay (2005) note, however, that television became an important advertising medium for beer firms during the period 1950 to 1964 (p. 52). Advertising also appears to be more intense among liquor firms. As a percent of sales, advertising in the liquor industry is nearly double that of the beer industry. Tremblay and Tremblay (2005), for example, show that advertising as a percent of sales in 2000 was $15.2 \%$ in the liquor industry, but only $8.6 \%$ in the beer industry (p. 171). The beer industry is also considerably more concentrated than the liquor industry. In 2003, the four-firm concentration ratio $\left(C R_{4}\right)$ was $98 \%$ in the beer industry (see Tremblay et. al. 2005), but only 50\% in the liquor industry (Adams Media, 2004). Lastly, beer case sales peaked in the early 1980s, and have trended downwards thereafter (see Nelson 2005, Tremblay and Tremblay 2005). Liquor case sales, by contrast, declined for a quarter century until 1996, and are currently in a period of increase (see Figure 1).

In this paper, we construct an unusually rich sample of 74 leading liquor brands over the period 1994 to 2004 . This sample is then used to evaluate the potential efficacy of partial advertising media 
restrictions through the construction of three different advertising media elasticities of substitution: the one-factor-one-price derived-demand elasticity of substitution, the two-factor-one-price Morishima elasticity of substitution, and the little used, but appropriate, two-factor-two-price shadow elasticity of substitution. The effectiveness of partial media advertising bans (e.g. a ban on the use of television advertising), depends on the absence of substitutable advertising media. We find that many of the advertising media used by liquor brands are highly substitutable, implying that partial media bans would prove ineffective.

The structure of the paper is as follows. Section 2 provides an overview of the data and the translog cost system estimation, including concerns over autocorrelation and functional form. Section 3 examines the substitutability of the advertising media used in the liquor industry. Section 4 offers a brief set of conclusions.

\section{Data and Translog Cost Estimation}

We collect annual advertising and case sales data for 74 leading liquor brands over the period 1994 to 2004. Descriptive statistics of the variables are presented in Table 1. The Data Appendix provides further detail on the construction of the data set. Six of the liquor brands in the sample are new brands, introduced after the year 1994. For this reason, the full sample is unbalanced, and consists of 777 observations. In the translog cost analysis, the first year for each brand is used only as a lagged value for the second year, causing the usable sample size to decrease to 703 observations. When the sample is limited to only brands that advertised during a given year, the number of observations falls by an additional 121, to the final data set size of 580 observations (see the estimation sample mean column in Table 1). Averaged over the sample period, our sample represents $58.9 \%$ of total industry case sales, and $77.7 \%$ of total advertising expenditures in the industry.

[Table 1 about here] 
Total advertising is segmented into four media groups: outdoor billboard advertising, print advertising, radio advertising, and television advertising. Print advertising includes advertising in magazines, newspapers, and Sunday magazines. Among liquor brands, the vast majority of print advertising is from magazines (95.7\% averaged annually over the sample period), while newspaper and Sunday magazine advertising are used quite sparingly (2.2\% and $2.1 \%$, respectively). Radio advertising includes both network and spot radio advertising. The vast majority of radio advertising is from spot radio advertising (99.6\% averaged annually over the sample period). Television advertising includes cable, network, spot, and syndicated television advertising. Among the components of television advertising, spot and cable television advertising are used most commonly (56.3\% and 40.9\%, respectively), while network and syndicated television advertising are used infrequently $(2.8 \%$ and less than $0.1 \%$, respectively).

Figure 2 shows recent trends in advertising expenditures by advertising media for brands in the sample, and the industry in total. The industry's use of print advertising, the largest of the four media, increased rapidly throughout the 1990 s, from \$205.9 million in 1994 to \$326.1 million in 2000 (in constant 2004 dollars). Expenditures on print advertising peaked in the year 2000, however, declining to $\$ 307.1$ million by the year 2004. By comparison, the use of outdoor billboard advertising has remained relatively constant, with annual industry expenditures averaging $\$ 40.0$ million per year between the years 1994 to 2004. Following the industry's decision to lift its voluntary restriction on radio and television advertising in 1996, radio advertising expenditures began an immediate and substantial increase. Between the years 1996 and 2002, expenditures on radio advertising increased from $\$ 3.2$ million to $\$ 27.2$ million, an increase of $750 \%$. Since 2002 , however, radio advertising expenditures have declined, falling to $\$ 14.3$ million in 2004. Television advertising expenditures, by contrast, remained relatively small until the year 2000. Since 2000, however, television advertising expenditures have increased at an astonishing rate. Between 2000 
and 2004, industry expenditures on television advertising increased twelve-fold, from $\$ 5.4$ million to \$68.1 million.

[Figure 2 about here]

Figure 3 shows trends in advertising costs within the four media groups. These data were provided by Robert J. Coen, Senior Vice President of Universal McCann, and are constructed as an index measure which quantifies the cost of each media per thousand viewers. Our sample period is a period of generally increasing media costs, though television media costs peaked in the year 2000, and declined significantly thereafter. This peak and post-2000 price decline in television may have been a contributing factor in the delayed usage of television media vis-à-vis radio media.

[Figure 3 about here]

\subsection{The Translog Cost System}

Advertising cost, $a$, may be expressed as the product of the quantity of advertising messages $\left(q^{A}\right)$

and the price of those advertising messages $\left(P^{A}\right)$. Given that a firm wishes to sell $q$ units of a brand, we assume there are several advertising media available for the firm to advertise in (i.e. print, outdoor, television, and radio). Thus the advertising cost minimization problem can be stated as

$$
\min _{\mathbf{q}^{\mathbf{A}}} a=\mathbf{q}^{\mathbf{A}} \mathbf{P}^{A} \quad \text { such that } \quad q=f\left(\mathbf{q}^{\mathbf{A}}\right),
$$

where $\mathbf{q}^{\mathbf{A}}$ is a row vector of advertising messages in the various media, $\mathbf{P}^{A}$ is a column vector of the prices for messages in the various media, $q$ is the output that the firm wishes to sell, and $f\left(\mathbf{q}^{\mathbf{A}}\right)$ is a quasiconcave twice differentiable advertising function that relates the number of advertising messages to the output the firm wishes to sell. The nature of this advertising function assumes advertising has a diminishing impact, a widely recognized property (see for example, Kadiyali 1996). ${ }^{11}$ In general, our approach follows Seldon, Jewell, and O'Brien (2000) in assuming that the 
production and advertising cost functions are separable, though we will later test this assumption with a homotheticity test.

In markets with rival brands, the advertising function can be written more completely as $f\left(\mathbf{q}^{\mathbf{A}} ; A, Q\right)$, where $A$ is the total advertising expenditures of rival brands, and $Q$ is the total cases sold by rival brands. A rival in this context is defined as other liquor brands within a liquor segment. We divide the liquor industry into eight liquor segments: brandy and cognac, cordials and liqueur, gin, prepared cocktails, rum, tequila, vodka, and whiskey. The inclusion of rival's advertising and case sales provides a more complete construction of the advertising cost function, and is a unique feature from prior translog advertising cost estimations (see for example, Silk et. al. 2002, Seldon et. al. 2000, and Seldon and Jung 1993).

The minimization problem results in the advertising cost function, $a=a\left(\mathbf{P}^{A} ; q, A, Q\right)$. To evaluate this function, we employ a translog (transcendental logarithmic) representation of a cost function. The translog form is derived via a second-order Taylor's series expansion in logarithms of a cost function of arbitrary form. ${ }^{12}$ It is widely noted for its flexibility of form, which for example, is a priori nonhomothetic. Since we are interested in input substitution elasticities, its high generality is useful because it allows the cross-price elasticities to vary along with advertising prices and expenditure shares. This is not true with the common log-log demand model. Suppressing time and brand subscripts, the translog advertising cost model is

$$
\begin{aligned}
\ln a=\alpha_{o} & +\alpha_{q}(\ln q)+\frac{1}{2} \alpha_{q q}(\ln q)^{2}+\sum_{i} \alpha_{q i}(\ln q)\left(\ln P_{i}^{A}\right)+\sum_{i} \beta_{i}\left(\ln P_{i}^{A}\right) \\
& +\frac{1}{2} \sum_{i} \sum_{j} \beta_{i j}\left(\ln P_{i}^{A}\right)\left(\ln P_{j}^{A}\right)+\gamma_{A}(\ln A)+\frac{1}{2} \gamma_{A A}(\ln A)^{2}+\sum_{i} \gamma_{A i}(\ln A)\left(\ln P_{i}^{A}\right) \\
& +\gamma_{A q}(\ln A)(\ln q)+\delta_{Q}(\ln Q)+\frac{1}{2} \delta_{Q Q}(\ln Q)^{2}+\sum_{i} \delta_{Q i}(\ln Q)\left(\ln P_{i}^{A}\right) \\
& +\delta_{Q q}(\ln Q)(\ln q)+\delta_{Q A}(\ln Q)(\ln A)+\mu+\tau+v,
\end{aligned}
$$


where $i, j$ are the four advertising media (outdoor, print, radio, and television), $\mu$ are firm dummies, $\tau$ are time dummies, and $v$ is the error term.

The optimal cost-minimizing share equations are found by employing Shephard's Lemma and differentiating (1) with respect to the natural log of the advertising prices:

$$
\frac{\partial \ln a}{\partial \ln P_{i}^{A}}=\frac{P_{i}^{A} q_{i}^{A}}{a}=S_{i}
$$

where $S_{i}$ is the cost share for the $i^{\text {th }}$-advertising media input. From the translog advertising cost function,

$$
S_{i}=\beta_{i}+\alpha_{q i}(\ln q)+\sum_{j} \beta_{i j}\left(\ln P_{j}^{A}\right)+\gamma_{A i}(\ln A)+\delta_{Q i}(\ln Q)
$$

for $i, j=$ outdoor, print, radio, and television.

By symmetry of second-order coefficients, $\beta_{i j}=\beta_{j i}$. For the cost function to be homogenous of degree one in advertising input prices, it must be the case that

(3) $\sum_{i} \beta_{i}=1, \sum_{i} \alpha_{q i}=0, \sum_{i} \beta_{i j}=0, \sum_{j} \beta_{j i}=0, \sum_{i} \gamma_{A i}=0$, and $\sum_{i} \delta_{Q i}=0$.

Hence, for a fixed level of output, total cost must increase proportionally when all advertising input prices increase proportionally.

By nature of their construction, the four share equations will sum to unity and result in a singular covariance matrix. To avoid this problem, one of the four share equations must be dropped. We arbitrarily dropped the outdoor advertising share equation, but can recover its parameter estimates using the restrictions defined in (3).

We assume that brand case sales $(q)$ are endogenous, and estimate the system via iterative three stage least squares (I3SLS). Case sales are instrumented with real disposable income per capita and the legal drinking age population.

\subsection{Autocorrelation}


In the initial estimation of the system, evidence of autocorrelation was found in all four of the equations. ${ }^{13}$ Berndt and Savin (1975) find that the singularity of the equation system implies that the contemporary disturbance covariance matrix will also be singular. Including all equations from an $n$-equation system, the first-order autoregressive $n \times 1$ vector of disturbances can be defined as

$$
v_{t}=\rho v_{t-1}+\varepsilon_{t}
$$

where $\boldsymbol{\rho}$ is an $n \times n$ matrix of unknown autoregressive parameters, and $\boldsymbol{\varepsilon}_{\mathbf{t}}$ is a $n \times 1$ vector of well-

behaved i.i.d. error terms. It is useful to partition the $\boldsymbol{\rho}$ matrix into a $(n-1) \times(n-1)$ submatrix of the share equation autoregressive parameters:

$$
\boldsymbol{\rho}^{S}=\left[\begin{array}{cccc}
\rho_{o o} & \rho_{o p} & \rho_{o r} & \rho_{o t} \\
\rho_{p o} & \rho_{p p} & \rho_{p r} & \rho_{p t} \\
\rho_{r o} & \rho_{r p} & \rho_{r r} & \rho_{r t} \\
\rho_{t o} & \rho_{t p} & \rho_{t r} & \rho_{t t}
\end{array}\right]
$$

where $o$ denotes outdoor, $p$ denotes the print share equation, $r$ denotes radio, and $t$ denotes television. Berndt and Savin (1975) show that the columns in the submatrix $\boldsymbol{\rho}^{S}$ will sum to the same unknown constant. However, $\boldsymbol{\rho}^{S}$ can be transformed by differencing each element from the autocorrelation coefficient of the media share that will be dropped (in our case, $\rho_{i j}-\rho_{i o}$, where $i, j=o, p, r$, and $t$ ).

The columns of $\overline{\boldsymbol{\rho}}^{S}$ now sum to zero. The singularity of the covariance matrix necessitates the removal of one share equation in the $n$-equation system (we arbitrarily dropped the outdoor share equation). With its removal, the full autocorrelation matrix, $\overline{\boldsymbol{\rho}}$, becomes a $(n-1) \times(n-1)$ matrix of autoregressive parameters:

$$
\overline{\boldsymbol{\rho}}=\left[\begin{array}{cccc}
\rho_{a a} & \rho_{a p}-\rho_{a o} & \cdots & \rho_{a t}-\rho_{a o} \\
\rho_{a p} & \rho_{p p}-\rho_{p o} & \cdots & \rho_{p t}-\rho_{p o} \\
\vdots & \vdots & \ddots & \vdots \\
\rho_{a t} & \rho_{t p}-\rho_{t o} & \cdots & \rho_{t t}-\rho_{t o}
\end{array}\right]
$$


The translog system of equations defined by the cost equation (1) and share equations (2) may then be estimated simultaneously with the autocorrelation parameters given in (4). ${ }^{14}$

\subsection{Functional Form and Estimation}

The translog functional form imposes minimal structure a priori. Post-estimation, however, we test three restrictions of the functional form: homotheticity, homogeneity, and constant returns to scale. For the translog to be homothetic, $\alpha_{q i}=0$ for all $i$. Homotheticity implies that the advertising cost function is separable in output and advertising input prices. For the translog to be homogenous (whereby the elasticity of cost with respect to output is constant), $\alpha_{q i}=0 \quad \forall i$ as before, and $\alpha_{q q}=0, \gamma_{A q}=0$, and $\delta_{Q q}=0$. For constant returns to scale, $\alpha_{q i}=0 \forall i, \alpha_{q q}=0$, $\gamma_{\mathrm{Aq}}=0$, and $\delta_{\mathrm{Qq}}=0$ as before, and $\alpha_{q}=1$.

Each of these restrictions may be tested using the likelihood ratio statistic. While the likelihood ratio statistic for homotheticity is an insignificant $5.75,(p$-value $=0.124)$, the other test statistics are statistically significant at the $5 \%$ level. ${ }^{15}$ Hence, the homothetic model is appropriate for the sample period.

The translog cost equation (1) can be estimated with firm and year dummy variables. Using the likelihood ratio test statistic, we find the firm dummy variables $(\mu)$ to be jointly significant (test statistic $=103.54, \mathrm{p}$-value $=0.001)$, while the time dummy variables $(\tau)$ are jointly insignificant (test statistic $=9.62, \mathrm{p}$-value $=0.382$ ). The firm dummy variables are therefore included in the translog estimation, and the year dummies are dropped.

Table 2 provides the I3SLS parameter estimates for the translog system defined by equations (1) and (2), and subject to restrictions given in (3). In the estimation the output share equation is omitted, and the error term follows the AR(1) form defined in (4). ${ }^{16}$ The overall fit of the model is 
good (the adjusted $\mathrm{R}^{2}$ for the translog cost equation is near 0.7 ), and the Durbin-Watson test statistics do not indicate the presence of additional autocorrelation. ${ }^{17}$

[Table 2 about here]

\section{Advertising Media Elasticities of Substitution}

The principle of substitutability suggests that firms banned from using one advertising medium could maintain a constant level of output by increasing their use of a second advertising medium, if the second medium is substitutable for the first. Hence, the effectiveness of a partial advertising media ban depends on the absence of substitutable media. Our sample is well suited for accessing advertising substitutability since the considerable changes in case sales and advertising practices over the sample period (see Figures 1 and 2) will enable proper identification of the underlining effects. To assess media substitutability from a many-input cost function, several alternative unit free measures can be constructed. Chambers (1988) organizes these alternatives into three useful categories: one-factor-one-price elasticities of substitution (OOES), two-factor-one-price elasticities of substitution (TOES), and two-factor-two-price elasticities of substitution (TTES). We are interested in measures from each of the three categories of substitutability. ${ }^{18}$

The derived-demand price elasticity of substitution and the Allen elasticity of substitution are OOES. Following Chambers (1988), the cross-price and own-price derived-demand elasticities are defined as

$$
\varepsilon_{i j}=\frac{\partial \ln S_{i}}{\partial \ln P_{j}^{A}}, \text { and } \quad \varepsilon_{i i}=\frac{\partial \ln S_{i}}{\partial \ln P_{i}^{A}},
$$

where $S_{i}$ is the estimated share of total advertising for media $i$, and $P_{j}^{A}$ is the price of advertising in media $j$. These derived-demand price elasticities can be expressed as

(5) $\varepsilon_{i j}=\frac{\beta_{i j}+S_{i} S_{j}}{S_{i}}$, and $\varepsilon_{i i}=\frac{\beta_{i i}+S_{i}^{2}-S_{i}}{S_{i}}$, 
where $\beta_{i j}$ and $\beta_{i i}$ are translog cost system parameters reported in Table 2 . These elasticities are classified as OOES because they portray the percent change in the use of one advertising medium from a one percent change in the price of one other advertising medium. Inputs $i$ and $j$ are denoted derived-demand substitutes if $\varepsilon_{i j}>0$, and derived-demand complements if $\varepsilon_{i j}<0$.

The related Allen elasticity of substitution was constructed originally by Allen (1938) and Uzawa (1962). Following Chambers (1988) and Blackorby and Russell (1989), the Allen elasticity can be expressed as

(6) $\quad \sigma_{i j}^{A}=\frac{\varepsilon_{i j}}{S_{j}}$, and $\sigma_{i i}^{A}=\frac{\varepsilon_{i i}}{S_{i}}$.

Notice that the Allen elasticity provides little new information beyond the derived-demand elasticity.

Dividing the price elasticity by the cost share removes the asymmetric information of the elasticity (because $S_{i} S_{j}=S_{j} S_{i}$ ). Although Allen elasticities were the principal elasticity of substitution reported in early empirical work (see for example, Christensen and Green 1976, and Brendt and Wood 1975), they have since been significantly criticized as uninformative by Blackorby and Russell (1989) and Chambers (1988). We follow these criticisms and only report the derived-demand elasticities, though the Allen elasticities may be easily recovered from equation (6).

The Morishima elasticity of substitution is a TOES. Originated by Morishima (1967), the Morishima elasticity measures the percent change in the media input ratio from a one percent change in the price of an input:

$$
\sigma_{i j}^{M}=\frac{\partial \ln \left(S_{i} / S_{j}\right)}{\partial \ln \left(P_{j}^{A}\right)} .
$$

This can be shown to be equivalent to (see Chambers 1988, Blackorby and Russell 1989)

(7) $\quad \sigma_{i j}^{M}=\varepsilon_{i j}-\varepsilon_{j j}$. 
Like derived-demand elasticities, Morishima elasticities are generally not symmetric, $\sigma_{i j}^{M} \neq \sigma_{j i}^{M}$.

Media $i$ and $j$ are said to be Morishima-substitutes if an increase in $P_{j}^{A}$ causes the input share ratio $\left(S_{i} / S_{j}\right)$ to rise, and hence $\sigma_{i j}^{M}>0$. Similarly, media $i$ and $j$ are Morishima-complements if $\sigma_{i j}^{M}<0$. For comparison purposes, note that the Morishima elasticities will equal unity in the CobbDouglas two-input case (see Blackorby and Russell 1989).

For a TTES, the shadow elasticity of substitution may be calculated. The shadow elasticity shows the percentage adjustment in the media input ratio from a change in the media price ratio:

$$
\sigma_{i j}^{S}=\frac{\partial \ln \left(S_{i} / S_{j}\right)}{\partial \ln \left(P_{i}^{A} / P_{j}^{A}\right)} .
$$

Following Chambers (1988), the shadow elasticity can be expressed as the share-weighted average of two Morishima elasticities:

$$
\sigma_{i j}^{S}=\frac{S_{i}}{S_{i}+S_{j}} \sigma_{i j}^{M}+\frac{S_{j}}{S_{i}+S_{j}} \sigma_{j i}^{M},
$$

Notice that the shadow elasticities are symmetric, $\sigma_{i j}^{S}=\sigma_{j i}^{S}$. Although shadow elasticities have not been used in prior empirical work, they are, nevertheless, appropriate. As Chambers (1988) shows, the shadow elasticities are closest in concept to Hicks' two-factor elasticity of substitution (p. 99). The estimated derived-demand price elasticities of substitution are presented in Table 3. Panel A in Table 3 presents the elasticities measured at the sample mean, as is common in the literature. From Figure 2, however, it is clear that the mix of advertising media used at the end of the sample is different from the advertising mix used at the beginning. Therefore, Panel B in Table 3 presents the elasticities measured at the final year of the sample, a period more reflective of current advertising usage. The estimated derived-demand own-price elasticities are shown along the main diagonal. Confidence intervals are calculated via bootstrapping. ${ }^{19}$ Print and television $\left(\hat{\varepsilon}_{p p}\right.$ and $\left.\hat{\varepsilon}_{t t}\right)$ are both statistically significant and large in magnitude, indicating that demand for each is elastic. (All of the 
own-price elasticities are negatively signed, as one would expect.) The off-diagonal evidence indicates that print and outdoor $\left(\hat{\varepsilon}_{p o}\right.$ and $\left.\hat{\varepsilon}_{o p}\right)$, and print and television $\left(\hat{\varepsilon}_{p t}\right.$ and $\left.\hat{\varepsilon}_{t p}\right)$ are deriveddemand substitutes. Outdoor and radio $\left(\hat{\varepsilon}_{\text {or }}\right.$ and $\left.\hat{\varepsilon}_{\text {or }}\right)$, by contrast, are derived-demand complements. Overall, the elasticities in Panels A and B are quite similar, with the notable exception of television share of advertising (i.e. when $i=$ television). In these four cases, the elasticities measured at the sample mean are three to five times larger in absolute value than the elasticities measured for the year 2004. This difference is due largely to the limited use of television advertising before the year 2000, which appears to have had a distorting impact on the television elasticities measured at the sample mean.

\section{[Table 3 about here]}

The Morishima elasticities are presented in Table 4. In general, most of the media in Table 4 are Morishima-substitutes (positively signed). Of the negatively signed elasticities, only radio and outdoor $\left(\hat{\sigma}_{\text {ro }}^{M}\right)$ is statistically significant, though this occurs only when measured at the mean of the sample. Print and television $\left(\hat{\sigma}_{p t}^{M}\right)$, outdoor and print $\left(\hat{\sigma}_{o p}^{M}\right)$, and television and print $\left(\hat{\sigma}_{t p}^{M}\right)$ are each positive and significant in both Panels. Outdoor and television $\left(\hat{\sigma}_{o t}^{M}\right)$ is positive and significant when measured for the year 2004, but not when measured at the sample mean.

\section{[Table 4 about here]}

Unlike the OOES derived-demand elasticities reported in Table 3, Morishima elasticities measure the relative input change from a single factor price change. To illustrate, notice that an increase in the price of television leads to a modest but statistically significant increase in the share of print advertising (from Table 3, $\hat{\varepsilon}_{p t}=0.876$ in Panel A, and 1.083 in Panel B). By contrast, the Morishima elasticities presented in Table 4 indicate that an increase in the price of television leads to a large and statistically significant increase in the share of print-to-television advertising, 
$\left(\hat{\sigma}_{p t}^{M}=10.625\right.$ in Panel A, and 4.255 in Panel B). The difference in magnitude between the deriveddemand and Morishima elasticities suggests that the own-price elasticity of demand for television is highly elastic, since the print-television share ratio $\left(S_{p} / S_{t}\right)$ is increasing faster than the share of print advertising $\left(S_{p}\right)$. From Table 3 this is easily verified; in Panel A, $\hat{\varepsilon}_{t t}=-9.749$, and in Panel $\mathrm{B}, \hat{\varepsilon}_{t t}=-3.172$.

The shadow elasticities of substitution are presented in Table 5. A shadow elasticity weights the two Morishima elasticities by their respective cost shares, and is closest in concept to Hicks' twofactor elasticity of substitution. With the exception of outdoor and radio $\left(\hat{\sigma}_{\text {or }}^{s}\right)$, all of the shadow elasticities are positive, and most indicate a relatively easy substitution process (i.e. most are greater than one in magnitude). When measured at the sample mean, two are statistically significant: print and outdoor $\left(\hat{\sigma}_{p o}^{S}\right)$, and print and television $\left(\hat{\sigma}_{p t}^{S}\right)$. When measured for the year 2004, a period more reflective of current advertising usage, three of the six elasticities are statistically significant: print and outdoor, print and television, and outdoor and television $\left(\hat{\sigma}_{\text {ot }}^{s}\right)$. Each of these three significant elasticities are positively signed, and each is large in magnitude, implying a relatively easy substitution process.

[Table 5 about here]

Taken together, the evidence from Tables 3, 4, and 5 imply that a partial ban on television advertising would likely be ineffective in reducing case sales of liquor. The derived-demand elasticities indicate that an increase in the price of television advertising leads to an increase in the use of print media $\left(\hat{\varepsilon}_{p t}=0.876\right.$ and 1.083 in Panels A and B of Table 3). When measured for the year 2004, the Morishima elasticities indicate that increases in the price of television lead to increases in the ratio of print-to-television media, and increases in the ratio of outdoor-to-television media. Hence, both print and outdoor media are Morishima-substitutes for television price changes 
$\left(\hat{\sigma}_{p t}^{M}=4.255\right.$ and $\hat{\sigma}_{o t}^{M}=2.985$ in Panel B of Table 4). Seldon, Jewell, and O'Brien (2000) find a similar relationship among beer firms over the period 1983-1993.20 The shadow elasticities in Table 5 further evaluate the impact of television price changes by considering the adjustment in the media input ratio from a change in the media price ratio. Under this derivation, print and outdoor media are

again found to be substitutes for television advertising $\left(\hat{\sigma}_{p t}^{S}=5.235\right.$ and $\hat{\sigma}_{o t}^{S}=2.454$ in Panel B of Table 5).

The efficacy of a ban on radio advertising, however, is less clear. From Table 3, an increase in the price of radio is found to decrease the use of outdoor advertising media, indicating they are derived-demand complements $\left(\hat{\varepsilon}_{\text {or }}=-2.084\right.$ and -2.129 in Panels A and B of Table 3). ${ }^{21}$ Silk, Klien, and Brendt (2002) find a similar relationship among national U.S. advertisers over the period 1960-1994. ${ }^{22}$ When one also considers the effect of a radio price increase on its own-price elasticity demand, however, the relationship disappears $\left(\hat{\sigma}_{o r}^{M}=0.290\right.$ and 0.086 in Panels A and B of Table 4). When changes in the media price ratio are taken into account, the shadow outdoor and radio elasticity is negatively signed, but not statistically significant $\left(\hat{\sigma}_{o r}^{S}=-1.064\right.$ and -1.167 in Panels A and $\mathrm{B}$ of Table 5). The impact of a radio price increase on the remaining two media, print and television, is not found to be statistically different from zero with any of the three elasticities of substitution.

\section{Conclusion}

This paper has presented empirical evidence on the substitutability of the advertising media used by liquor brands in the United States. The liquor industry in the U.S. has experienced a substantial turnaround since the mid-1990s. Between 1995 and 2004, liquor case sales increased by 21\%, and liquor advertising increased by $64 \%$. Moreover, the mix of advertising media used by liquor brands also changed substantially following the industry's decision in 1996 to break a long-standing ban 
against the use of radio and television media. Increases in liquor sales raise numerous public policy concerns, however, particularly given the high costs to society emanating from alcoholism, alcoholrelated traffic fatalities, and other alcohol-related health problems. Despite the importance of these concerns, this study is apparently the first to empirically evaluate the liquor industry since these changes began in the mid-1990s.

Using a rich sample of 74 leading liquor brands over the period 1994 to 2004, we discover through a translog cost estimation that the advertising media used by liquor brands are highly substitutable. This finding implies that the imposition of a partial media advertising ban would prove ineffective in reducing consumption. Twice over our sample period, bills have been introduced into the House of Representatives that would prohibit the use of television media for liquor advertising (H.R. 3644 in 1996, and H.R. 1067 in 1997). If such legislation were passed, our findings indicate that liquor brands could maintain case sales by increasing their utilization of print and outdoor media. The government, in effect, would be resolving the prisoner's dilemma for these firms by enforcing a cooperative solution of no-television advertising.

Many additional issues remain open for further investigation. Given the remarkable turnaround in liquor sales pictured in Figure 1, a thorough analysis on the determinants of liquor demand would be useful in furthering our findings. Moreover, some of the concern surrounding liquor advertising on television and radio relates specifically to the potential for these media to uniquely influence and inform young adults. ${ }^{23}$ While our results suggest that among consumers as a whole, the medium of television is substitutable for outdoor and print media, we lack the data to specifically evaluate its substitutability among young adults. Recent evidence on tobacco use by Goel and Nelson (2005), for example, indicates that responses to tobacco usage policies differ significantly between age cohorts. Our analysis also leaves aside the possibility of beverage-substitution. Nelson (2003) has shown that restrictive laws directed at only one form of alcohol (liquor, wine, or beer), may simply result in substitution to the other two forms. These are all important areas for future research to consider. 


\section{References}

Adams Media. Annual Issues 1997-2005. Adams Liquor Handbook. New York: Adams Media Inc.

Allen, R. G., D. 1938. Mathematical Analysis for Economists. London: Macmillan.

Anderson, Richard G., and Jerry G. Thursby. 1986. Confidence Intervals for Elasticity Estimators in Translog Models. Review of Economics and Statistics 68 (4, November):647-56.

Berndt, Ernst R., and N. Eugene Savin. 1975. Estimation and Hypothesis Testing in Singular Equation Systems with Autoregressive Disturbances. Econometrica 43 (5/6, Sept.-Nov.):93758.

Berndt, Ernst R., and David O. Wood. 1975. Technology, Prices, and the Derived Demand for Energy. Review of Economics and Statistics 57 (3, August):259-68.

Blackorby, C., and R. R. Russell. 1989. Will the Real Elasticity of Substitution Please Stand Up? (A Comparison of the Allen/Uzawa and Morishima Elasticities). American Economic Review $79: 882-88$

Brendt, Ernest R. 1991. The Practice of Econometrics: Classic and Contemporary. Reading, MA: Addison-Wesley.

Chambers, Robert G. 1988. Applied Production Analysis: A Dual Approach. Cambridge: Cambridge University Press.

Christensen, Laurits R., and William H. Greene. 1976. Economies of Scale in U.S. Electric Power Generation. Journal of Political Economy 84 (4, part 1, August):655-76.

Christensen, Laurits R., Dale W. Jorgenson, and Lawrence J. Lau. 1971. Conjugate Duality and the Transcendental Logarithmic Function. Econometrica 39 (4):255-56.

Competitive Media Reporting. Annual Issues 1994-2004. Multi-Media Class/Brand \$. New York: Competitive Media Reporting.

Gallet, Craig A. 1999. The Effect of the 1971 Advertising Ban on Behavior in the Cigarette Industry. Managerial and Decision Economics 20:299-303. 
Goel, Rajeev K., and Michael A. Nelson. 2005. Tobacco Policy and Tobacco Use: Differences Across Tobacco Types, Gender and Age. Applied Economics 37 (7, April):765-71.

Hemphill, Thomas A. 2002. A Prohibition on Advertising? Regulation 25 (1):8-10.

Jobson Publishing Corporation. 1995. Jobson's Liquor Handbook. New York: Jobson Publishing Corporation.

Jobson's Publishing Corporation. 1996. Adams / Jobson's Liquor Handbook. New York: Jobson's Publishing Corporation.

Kadiyali, Vrinda. 1996. Entry, its Deterrence, and its Accommodation: A Study of the U.S. Photographic Film Industry. RAND Journal of Economics 27 (3, Autumn):452-78.

Lee, Byunglak, and Victor J. Tremblay. 1992. Advertising and the US Market Demand for Beer. Applied Economics 24:69-76.

Leone, Robert P. 1995. Generalizing What is Known About Temporal Aggregation and Advertising Carryover. Marketing Science 14 (3):G141-50.

Morishima, M. 1967. On the Symmetry of Robinson Elasticities of Substitution (in Japanese). Keizai Hyoron (Economic Review) 16:144-50.

Mukamal, Kenneth J., Katherine M. Conigrave, Murray A. Mittleman, Carlos A. Camargo, Jr., Meir J. Stampfer, Walter C. Willett, and Eric B. Rimm. 2003. Roles of Drinking Pattern and Type of Alcohol Consumed in Coronary Heart Disease in Men. New England Journal of Medicine 348 (2, January 9):109-18.

National Highway Traffic Safety Administration. 2005. Traffic Safety Facts: 2004 Data. Washington D.C.: National Center for Statistics and Analysis.

National Institute of on Alcohol Abuse and Alcoholism. 2001. Alcoholism: Getting the Facts. NIH Publication No. 96-4153. National Institute of Health.

National Institute of on Alcohol Abuse and Alcoholism. 2002. Alcohol: What You Don't Know Can Harm You. NIH Publication No. 99-4323. National Institute of Health. 
Nelson, Jon P. 2003. Advertising Bans, Monopoly, and Alcohol Demand: Testing for Substitution Effects using State Panel Data. Review of Industrial Organization 22 (1):1-25.

Nelson, Jon P. 2005. Beer Advertising and Marketing Update: Structure, Conduct, and Social Costs. Review of Industrial Organization 26 (3, May):269-306.

Nelson, Jon P, and Douglas J. Young. 2001. Do Advertising Bans Work? An International Comparison. International Journal of Advertising 20 (3):273-96.

Saffer, Henry. 1991. Alcohol Advertising Bans and Alcohol Abuse: An International Perspective. Journal of Health Economics 10 (1, May):65-79.

Saffer, Henry. 1997. Alcohol Advertising and Motor Vehicle Fatalities. Review of Economics and Statistics 79 (3, August):431-42.

Saffer, Henry, and Frank Chaloupka. 2000. The Effect of Tobacco Advertising on Tobacco Consumption. Journal of Health Economics 19 (6, November):1117-37.

Saffer, Henry, and Dhaval Dave. 2002. Alcohol Consumption and Alcohol Advertising Bans. Applied Economics 34 (11, July):1325-34.

Seldon, Barry J, R. Todd Jewell, and Daniel M. O'Brien. 2000. Media Substitution and Economies of Scale in Advertising. International Journal of Industrial Organization 18 (8):1153-80.

Seldon, Barry J, and C. Jung. 1993. Derived Demand for Advertising Messages and Substitutability Among the Media. Quarterly Review of Economics and Finance 33 (1):71-86.

Silk, Alvin J., Lisa R. Klein, and Ernst R. Berndt. 2002. Intermedia Substitutability and Market Demand by National Advertisers. Review of Industrial Organization 20 (2, June):323-48.

Tremblay, Carol H., and Victor J. Tremblay. 1995. Advertising, Price, and Welfare: Evidence From the U.S. Brewing Industry. Southern Economic Journal 62:367-81.

Tremblay, Victor J., and Carol Horton Tremblay. 2005. The U.S. Brewing Industry: Data and Economic Analysis. Cambridge, Massachusetts: MIT Press. 
Uzawa, Hirofumi. 1962. Production Functions with Constant Elasticities of Substitution. Review of Economic Studies 29 (4, October):291-99. 


\section{Acknowledgements}

I thank Edward Blackburne, Donald Freeman, Berry Seldon, and seminar participants at the International Industrial Organization Conference (2006) for helpful comments on earlier versions of this article. Thanks also to Gabi Eissa and Sadaf Monam for their excellent assistance in construction of the sales and advertising data, and Robert Coen of Universal McCann for providing the advertising media cost data. I am grateful for the financial support provided by State of Texas through its Texas Excellence Fund, and by Sam Houston State University through its Faculty Research Grant. All errors remain my responsibility.

\section{Notes}

${ }^{1}$ Recent evidence indicates that light to moderate consumption of alcohol has some beneficial effects. A 2003 study published in the New England Journal of Medicine, for example, found that men who drank three to seven days a week had a 30\% lower risk of coronary heart disease than those that drank less than once a week (Mukamal, et. al. 2003).

${ }^{2}$ We use the term liquor to mean all distilled spirits and liqueurs. These types of alcoholic beverages have high alcohol content (at least 35\% by volume), and in the case of liqueurs, are also high in sugar. Liquor excludes, therefore, wine $(10 \%-20 \%$ alcohol by volume), beer $(3 \%-8 \%)$, and malternatives $(4 \%-7 \%)$. ${ }^{3}$ This self-regulated agreement was part of the industry's "Code of Good Practices" approved on October 27, 1934. The Code has since been continually updated, and is currently maintained by DISCUS, the industry's national trade association.

${ }^{4}$ Compliance with the voluntary ban was never perfect. Most notably, Allied Domecq began airing spot TV ads for its Presidente brandy in 1991 on Spanish-language channels. As Figure 2 indicates, these expenditures were very small in magnitude.

${ }^{5}$ For a sample of President Clinton's public comments, see the June 15, 1996 "Presidential Radio Address on Supporting Fathers" and the November 9, 1996 "Presidential Radio Address on Strengthening American Families." 
${ }^{6}$ Rep. Kennedy's “Just So No Act” was introduced on two separate occasions. Once on June 13, 1996 (H.R. 3644), and a second time on March 13, 1997 (H.R. 1067). Both bills were referred to subcommittees where no further actions have since been taken.

${ }^{7}$ As a result of this agreement, the first network TV liquor ad in U.S. history aired on December 15th of that year on the NBC late night program "Saturday Night Live". As part of the contract, Diageo agreed to nineteen specific guidelines intended to limit children and teenagers' exposure to liquor commercials.

${ }^{8}$ The literature on cigarette advertising may also be of interest here. Exploiting cross-national variations in the advertising media available to cigarette firms, Saffer and Chaloupka (2000) find that partial advertising media bans have little or no effect on consumption. Comprehensive advertising bans, however, are found to be effective in reducing tobacco consumption.

${ }^{9}$ In Saffer (2002), advertising bans are converted to a discrete count variable. When country dummies are included in the equations, the advertising ban variable becomes insignificant. When the dummies are absent, however, the ban variable is significant at the 10 percent level.

${ }^{10}$ Saffer (1997) recognizes this point, "if a ban on broadcast advertising resulted in a complete substitution to other media and no reduction in the marginal product of advertising in other media, than the ban would have no effect at all” (p. 441).

${ }^{11}$ Leone (1995) analyses several empirical studies on the duration of advertising effects, and concludes that a 90 percent duration interval of six to nine months is typical.

${ }^{12}$ For the original derivation see Christensen, Jorgenson, and Lau (1971). For a more recent interpretation, see Berndt (1991) chapter 9.

${ }^{13}$ The Durbin-Watson test statistics for the total cost, print share, radio share, and television share equations are $0.505,0.760,1.037$, and 0.854 respectively. Each of these is statistically significant at the $5 \%$ level, indicating the presence of first-order autocorrelation.

${ }^{14}$ In our estimation, each $\left(\rho_{i j}-\rho_{i o}\right)$ element in $\overline{\boldsymbol{\rho}}^{S}$ is treated as a single parameter. Derivation of all the individual elements (i.e. $\rho_{i j}$ and $\rho_{i o}$ ) in $\overline{\boldsymbol{\rho}}^{S}$ is not pursued because identification is problematic, and economically uninteresting (see Brendt and Savin 1975). 
${ }^{15}$ The likelihood ratio statistics for homogeneity and constant returns to scale are: $15.91(p$-value $=0.014)$, and $25.25(\mathrm{p}$-value $=0.001)$.

${ }^{16}$ The brand shares of outdoor, print, radio, and television advertising at the sample mean are $0.270,0.628$, 0.074 , and 0.028 . For the year 2004, the shares are $0.263,0.546,0.083$, and 0.108 .

${ }^{17}$ The Durbin-Watson test statistics for the total cost, print, radio, and television share equations are 1.796, $1.952,2.106$, and 1.764 respectively. Each of these is not statistically significant at the $5 \%$ level, indicating no evidence of additional autocorrelation.

${ }^{18}$ Chambers (1988) highlights the difficulties in defining a meaningful measure of substitution in the manyinput case, and the resulting need for all three measures. With three measures of the same phenomenon, one should not, however, expect uniformity in the classifying of inputs as complements and substitutes (see chapters 1 and 3 in Chambers for a discussion).

${ }^{19}$ Bootstrapped confidence intervals are based on 2,000 random samples drawn with replacement. Bootstrapping is useful in the translog context because these elasticities are highly nonlinear functions of the parameter estimates. Anderson and Thursby (1986) provide a discussion on the difficulties in analytically deriving standard errors in the translog context. Bootstrapping of confidence intervals also allows for nonlinearity in the statistical distribution.

${ }^{20}$ Seldon, et. al (2000) group outdoor and print media into one composite "print" category. Interestingly, they find radio and television to be statistically significant Morishima-substitutes among beer firms.

${ }^{21}$ Silk, et. al. (2002) estimate spot radio and network radio separately, however. While spot radio and outdoor are found to be derived-demand complements, network radio and outdoor are found to be derived-demand substitutes. Silk, et. al., however, do not calculate the Morishima or the shadow elasticity of substitution. ${ }^{22}$ Viewing the input isoquant from the other direction, however, reveals that an increase in the price of outdoor advertising reduces the share of radio, as well as the ratio of radio-to-outdoor. Hence, when outdoor media prices change, radio and outdoor are derived-demand complements, and Morishima-complements.

${ }^{23}$ In 2003, the liquor industry increased its adult demographic provision from $50 \%$ to $70 \%$. As a result, liquor advertising is to be placed only in media where at least $70 \%$ of the audience is reasonably expected to be 21 
years of age or older. This provision is a part of the industry's "Code of Responsible Practices" maintained and enforced by DISCUS. 


\section{Data Appendix}

The data are collected annually for the period 1994 to 2004. There are 74 liquor brands in the data set. Six of these brands, however, were introduced during the sample period (Belvedere, Chopin, E\&J Cask and Cream, Grey Goose, Hpnotiq, and Seagram’s Vodka), resulting in an unbalanced sample of 777 total observations. Appendix Table 1 lists each brand alphabetically, along with the brand's liquor segment, supplying firm, mean case sales, and mean advertising expenditures. Notice that many of the liquor brands were sold and acquired by new suppliers during the sample period. (Of the 74 brands, 40 such exchanges occurred during the sample period.) The merger of Grand Metropolitan and United Distillers into Diageo in December of 1997, and the dissolution of Seagram in December of 2001, were significant contributors to this high frequency.

Annual brand-level nine-liter case sales data are taken from yearly issues of Adams Liquor Handbook (Adams Media, 1997-2005), Adams / Jobson’s Liquor Handbook (Jobson’s Publishing Corporation, 1996), and Jobson’s Liquor Handbook (Jobson Publishing Corporation, 1995). Brandlevel advertising expenditures are taken from yearly issues of Multi-Media Class/Brand \$. (Competitive Media Reporting, 1994-2004). This publication tracks total advertising expenditures, as well as expenditures within ten separate national media: magazines, Sunday magazines, newspapers, outdoor, network TV, spot TV, syndicated TV, cable TV, network radio, and spot radio. Case sales and advertising expenditures are deflated using the producer price index for distilleries, available from the web site of the Bureau of Labor Economics $(2004=100)$.

Advertising media price data were provided by Robert J. Coen, Senior Vice President of Universal McCann. This data was deflated using the consumer price index for all urban consumers (CPI-U), available from the web site of the Bureau of Labor Statistics $(2004=100)$. Note that the media price data reflect standardized national advertising rates, thus all brands in the sample face the same prices for advertising in a given media. Real disposable income per capita (in chained 2000 dollars) is taken from the National Accounts Data available at the web site of the Bureau of 
Economic Analysis. Legal age population (20 and older) is taken from the Population Estimates data web site of the U.S. Census Bureau. 
Figure 1. Trends in U.S. Liquor Sales and Advertising, 1980 - 2004

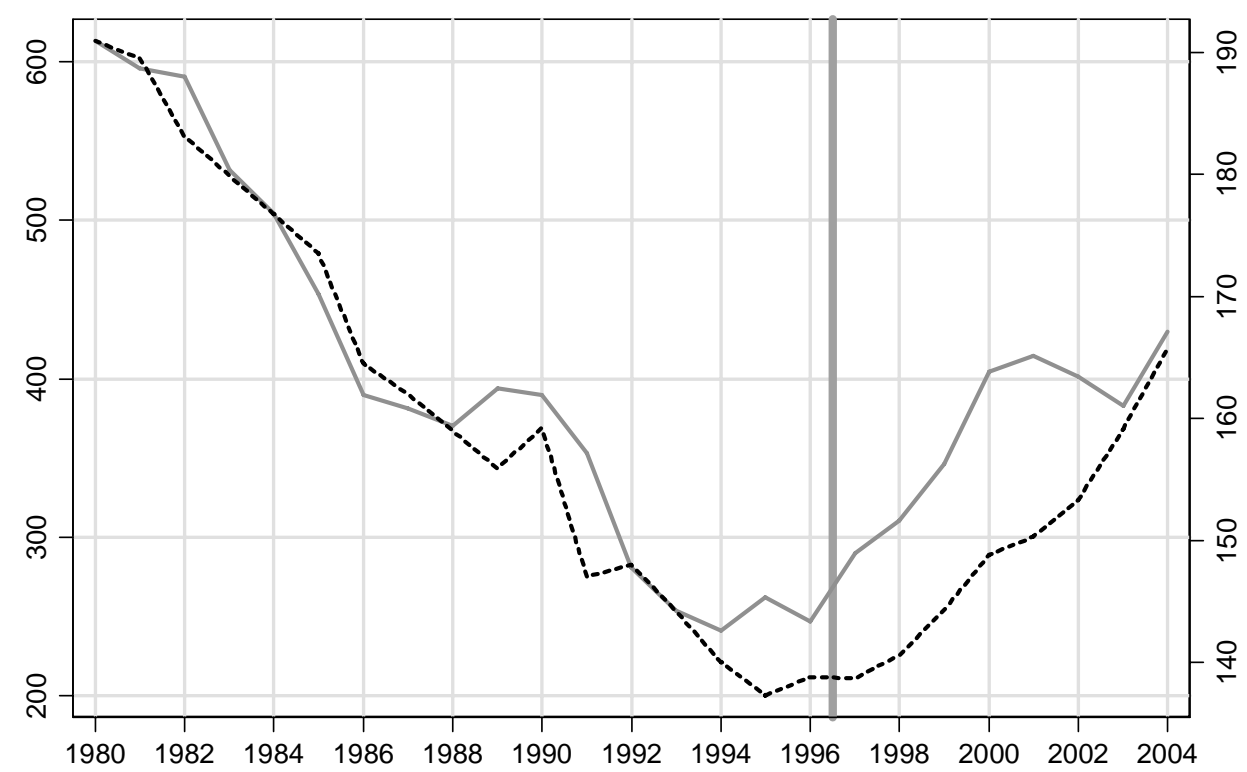

Annual Advertising Expenditures, in millions (left scale)

Annual 9-Liter Case Sales, in thousands (right scale) 
Figure 2. Trends in Liquor Advertising Expenditures (in millions) by Media Type, 1994 - 2004
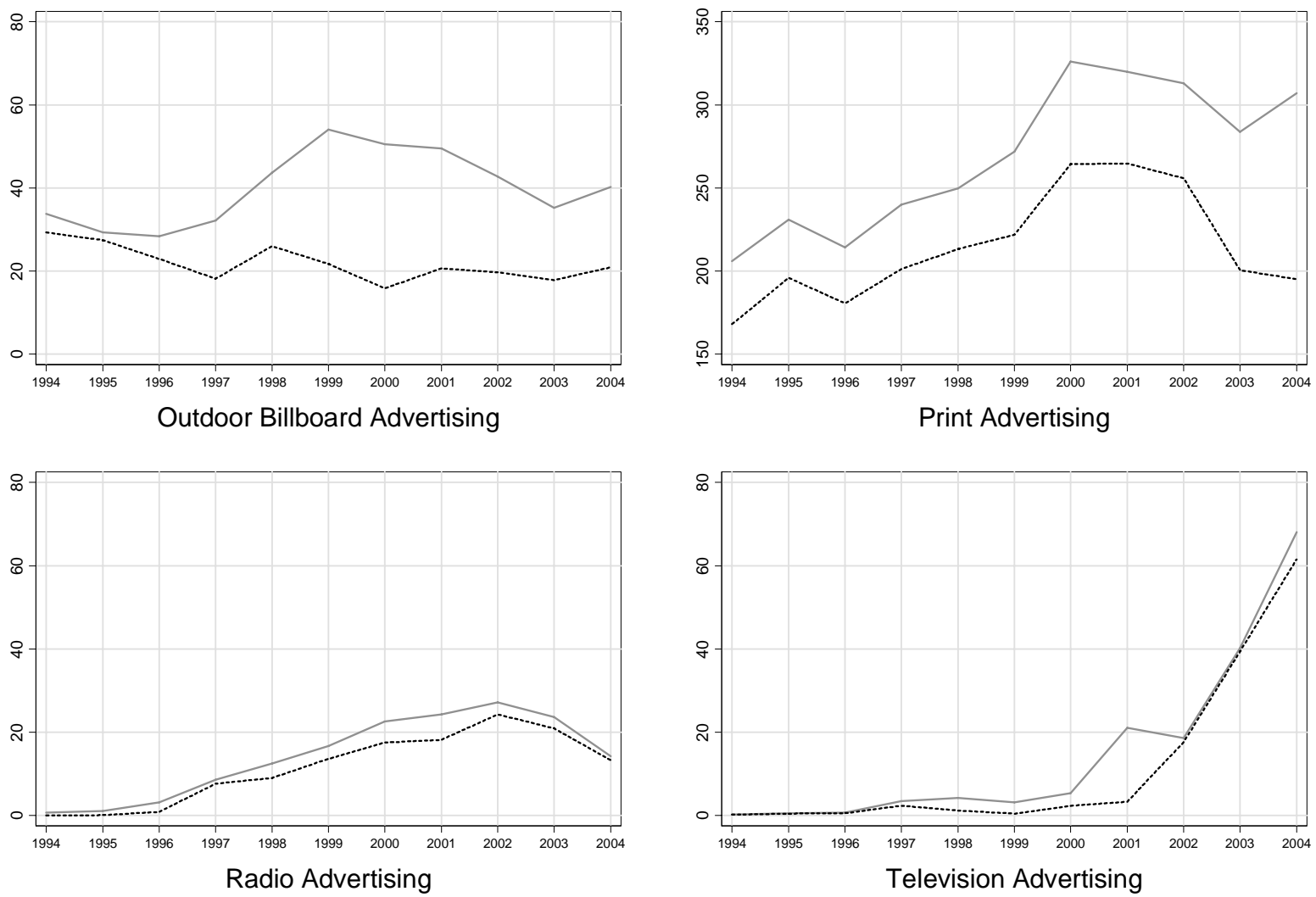

Trends in Industry

Trends in Sample 
Figure 3. Advertising Media Cost Per Thousand Viewers

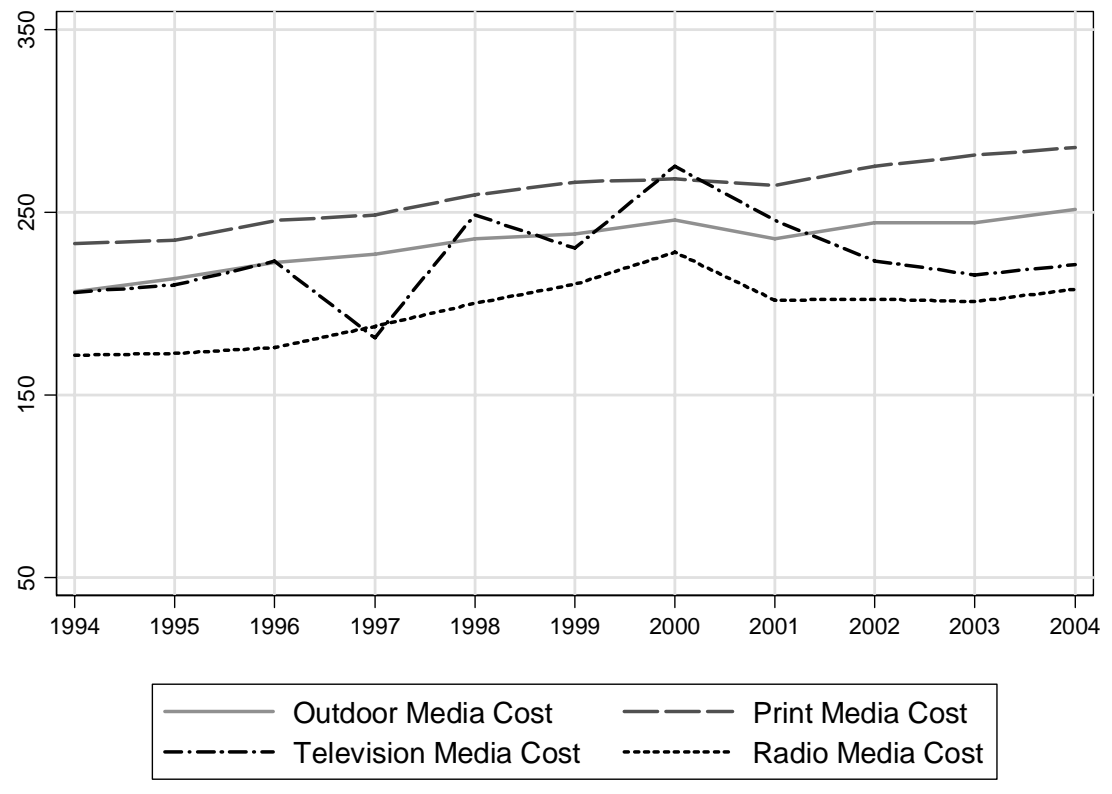


Table 1. Descriptive Statistics

\begin{tabular}{|c|c|c|c|c|}
\hline Variable & $\begin{array}{l}\text { Full Sample } \\
\text { Mean }^{\mathrm{a}}\end{array}$ & $\begin{array}{c}\text { Standard } \\
\text { Deviation }^{\text {a }}\end{array}$ & $\begin{array}{c}\text { Estimation } \\
\text { Sample Mean }^{\mathrm{b}}\end{array}$ & $\begin{array}{l}\text { Mean for } \\
\text { Year } 2004\end{array}$ \\
\hline Nine-Liter Case Sales & $1,224.9$ & $1,350.2$ & $1,360.0$ & 1569.5 \\
\hline Total Advertising Expenditures & $3,677.3$ & $6,013.0$ & $4,554.2$ & 4847.7 \\
\hline Outdoor Advertising Expenditures & 309.7 & 608.1 & 361.8 & 348.6 \\
\hline Print Advertising Expenditures & 3,039.8 & $5,346.3$ & $3,756.5$ & $3,253.0$ \\
\hline Radio Advertising Expenditures & 161.5 & 472.3 & 214.8 & 222.0 \\
\hline Television Advertising Expenditures & 166.4 & 979.9 & 221.1 & $1,024.1$ \\
\hline Outdoor Media Cost (CPM) & 233.6 & 13.6 & 236.1 & 251.7 \\
\hline Print Media Cost (CPM) & 260.8 & 17.0 & 263.3 & 285.6 \\
\hline Radio Media Cost (CPM) & 196.7 & 16.7 & 199.0 & 207.8 \\
\hline Television Media Cost (CPM) & 225.8 & 23.5 & 227.7 & 221.2 \\
\hline Real Disposable Income Per Capita & $24,555.2$ & $1,808.2$ & $24,793.1$ & $27,230.0$ \\
\hline Legal Age Population (millions) & 197.9 & 9.2 & 198.9 & 212.1 \\
\hline
\end{tabular}

Note: ${ }^{a}$ Sample includes all 777 observations. ${ }^{\mathrm{b}}$ Sample excludes the year 1994 and non-advertising brands (580 observations). 
Table 2. I3SLS Parameter Estimates of the Translog Cost and Share System of Equations

\begin{tabular}{|c|c|c|c|c|c|c|c|c|}
\hline Parameter & Estimate & (std.err.) & Parameter & Estimate & (std.err.) & Parameter & Estimate & (std.err.) \\
\hline$\alpha_{0}$ & -49.586 & $(20.93)^{* *}$ & $\gamma_{A r}$ & 0.073 & $(0.03)^{* * *}$ & Heaven Hill & 1.068 & $(0.42)^{* *}$ \\
\hline$\alpha_{q}$ & -0.561 & $(1.65)$ & $\gamma_{A t}$ & 0.025 & $(0.01)^{*}$ & Jim Beam & -1.860 & $(0.35)^{* * *}$ \\
\hline$\alpha_{q q}$ & 0.436 & $(0.16)^{\star * *}$ & $\delta_{Q}$ & 8.382 & $(4.70)^{*}$ & Kobrand Corp. & -0.666 & $(0.58)$ \\
\hline$\beta_{p}$ & 1.846 & $(0.75)^{\star *}$ & $\delta_{Q Q}$ & -1.199 & $(0.72)^{*}$ & Millennium Import & 0.369 & $(0.69)$ \\
\hline$\beta_{r}$ & -0.098 & $(0.38)$ & $\delta_{Q q}$ & 0.026 & $(0.27)$ & Moet Hennessy USA & 0.348 & $(1.21)$ \\
\hline$\beta_{t}$ & 0.266 & $(0.31)$ & $\delta_{Q p}$ & 0.029 & $(0.08)$ & Pernod Ricard & 0.3145 & $(0.43)$ \\
\hline$\beta_{p p}$ & -2.324 & $(1.04)^{* *}$ & $\delta_{Q r}$ & -0.119 & $(0.04)^{* * *}$ & Schieffelin \& Somerset & 0.144 & $(0.31)$ \\
\hline$\beta_{r r}$ & -0.108 & $(0.93)$ & $\delta_{Q t}$ & -0.055 & $(0.03)^{*}$ & Seagram & 0.075 & $(0.32)$ \\
\hline$\beta_{t t}$ & -0.245 & $(0.18)$ & $\delta_{Q A}$ & 0.422 & $(0.50)$ & Sidney Frank & -0.290 & $(0.58)$ \\
\hline$\beta_{p r}$ & 0.900 & $(0.90)$ & Absolut Spirits (V\&S) & 0.587 & $(0.91)$ & Skyy Spirits & -0.081 & $(0.47)$ \\
\hline$\beta_{p t}$ & 0.533 & $(0.30)^{*}$ & Bacardi USA & -0.006 & $(0.39)$ & Star Industries & -3.834 & $(1.02)^{* * *}$ \\
\hline$\beta_{r t}$ & -0.210 & $(0.29)$ & Brown-Forman & -0.735 & $(0.30)^{* *}$ & United Distillers & 0.352 & $(1.22)$ \\
\hline$\gamma_{A}$ & 2.324 & $(2.62)$ & Constellation & -1.471 & $(0.36)^{\star * *}$ & $\bar{R}^{2}$ & 0.668 & \\
\hline$\gamma_{A A}$ & -0.568 & $(0.40)$ & Diageo & -0.690 & $(0.33)^{* *}$ & $\bar{R}_{p}^{2}$ & 0.477 & \\
\hline$\gamma_{A q}$ & -0.181 & $(0.23)$ & E\&J Gallo & -4.162 & $(0.68)^{* * *}$ & $\bar{R}_{r}^{2}$ & 0.331 & \\
\hline$\gamma_{A p}$ & -0.050 & $(0.05)$ & Grand Metropolitan & -1.101 & $(0.36)^{\star * *}$ & $\bar{R}_{t}^{2}$ & 0.510 & \\
\hline
\end{tabular}

Note: ${ }^{*}, * *$, and ${ }^{* *}$ indicate significance at the $10 \%, 5 \%$, and $1 \%$ levels. Subscripts: $q=$ own case sales, $p=$ print, $r=$ radio, $t$

= television, $A=$ total advertising expenditures by rival brands, and $Q=$ total case sales by rival brands. Outdoor is the omitted share equation, Allied Domecq is the omitted firm dummy. The estimated autocorrelation parameters are not reported, but available upon request from the author. 
Table 3. Derived-Demand Price Elasticities of Substitution (OOES)

\begin{tabular}{|c|c|c|c|c|}
\hline$\left(\hat{\varepsilon}_{i j}\right)$ & $j=$ Print & $j=$ Outdoor & $j=$ Radio & $j=$ Television \\
\hline \multicolumn{5}{|c|}{ (A) At the Sample Mean } \\
\hline$i=$ Print & $-4.072^{* *}$ & $1.689^{* *}$ & 1.507 & $0.876^{*}$ \\
\hline$i=$ Outdoor & $3.933^{* *}$ & -1.589 & $-2.084^{*}$ & -0.260 \\
\hline$i=$ Radio & 12.744 & $-7.572^{*}$ & -2.374 & -2.798 \\
\hline$i=$ Television & $19.695^{*}$ & -2.513 & -7.434 & $-9.749^{*}$ \\
\hline \multicolumn{5}{|c|}{ (B) For the year 2004} \\
\hline$i=$ Print & $-4.710^{* *}$ & $1.895^{* *}$ & 1.730 & $1.083^{*}$ \\
\hline$i=$ Outdoor & $3.933^{* *}$ & -1.616 & $-2.129^{*}$ & -0.188 \\
\hline$i=$ Radio & 11.401 & $-6.762^{*}$ & -2.215 & -2.424 \\
\hline$i=$ Television & $5.499^{*}$ & -0.460 & -1.868 & $-3.172^{* *}$ \\
\hline
\end{tabular}

Note: ${ }^{*} * *$, and ${ }^{* * *}$ indicate significance at the $10 \%, 5 \%$, and $1 \%$ levels. 
Table 4. Morishima Elasticities of Substitution (TOES)

\begin{tabular}{|r|c|c|c|c|}
\hline \multicolumn{1}{|c|}{$\left(\hat{\sigma}_{i j}^{M}\right)$} & $j=$ Print & $j=$ Outdoor & $j=$ Radio & $j=$ Television \\
\hline (A) At the Sample Mean & \multicolumn{3}{|c|}{} \\
\hline$i=$ Print & 0 & 3.278 & 3.881 & $10.625^{*}$ \\
\hline$i=$ Outdoor & $8.005^{* *}$ & 0 & 0.290 & 9.489 \\
\hline$i=$ Radio & 16.816 & $-5.983^{*}$ & 0 & 6.951 \\
\hline$i=$ Television & $23.767^{* *}$ & -0.924 & -5.059 & 0 \\
\hline (B) For the year 2004 & & & \\
\hline$i=$ Print & 0 & 3.511 & 3.945 & $4.255^{* *}$ \\
\hline$i=$ Outdoor & $8.640^{* *}$ & 0 & 0.086 & $2.985^{*}$ \\
\hline$i=$ Radio & 16.108 & -5.146 & 0 & 0.749 \\
\hline$i=$ Television & $10.207^{* *}$ & 1.157 & 0.347 & 0 \\
\hline
\end{tabular}

Note: ${ }^{*}, * *$, and ${ }^{* * *}$ indicate significance at the $10 \%, 5 \%$, and $1 \%$ levels. 
Table 5. Shadow Elasticities of Substitution (TTES)

\begin{tabular}{|c|c|c|c|c|}
\hline$\left(\hat{\sigma}_{i j}^{S}\right)$ & $j=$ Print & $j=$ Outdoor & $j=$ Radio & $j=$ Television \\
\hline \multicolumn{5}{|c|}{ (A) At the Sample Mean } \\
\hline$i=$ Print & 0 & $4.698^{* *}$ & 5.249 & $11.185^{*}$ \\
\hline$i=$ Outdoor & & 0 & -1.064 & 8.511 \\
\hline$i=$ Radio & & & 0 & 3.667 \\
\hline$i=$ Television & & & & 0 \\
\hline \multicolumn{5}{|c|}{ (B) For the year 2004} \\
\hline$i=$ Print & 0 & $5.180^{* *}$ & 5.547 & $5.235^{* * *}$ \\
\hline$i=$ Outdoor & & 0 & -1.167 & $2.454^{*}$ \\
\hline$i=$ Radio & & & 0 & 0.522 \\
\hline$i=$ Television & & & & 0 \\
\hline
\end{tabular}

Note: ${ }^{*}, * *$, and ${ }^{* * *}$ indicate significance at the $10 \%, 5 \%$, and $1 \%$ levels. 
Appendix Table 1. Descriptive Statistics of Liquor Brands in Sample

\begin{tabular}{|c|c|c|c|c|}
\hline Liquor Brand & Segment & Supplier(s) & $\begin{array}{l}\text { Mean 9-Liter } \\
\text { Case Sales }\end{array}$ & $\begin{array}{l}\text { Mean Advertising } \\
\text { Expenditures }\end{array}$ \\
\hline Absolut & Vodka & Absolut Spirits (Seagram, -2000) & $3,886.6$ & $31,791.2$ \\
\hline Alize & Cordials and Liqueurs & Kobrand & 490.5 & $1,285.7$ \\
\hline Bacardi (all flavors) & Rum & Bacardi USA & $7,204.5$ & $20,799.9$ \\
\hline Baileys & Cordials and Liqueurs & Diageo (Grand Metropolitan, -1997) & 994.9 & $6,914.0$ \\
\hline Barton Gin & Gin & Constellation & 356.2 & 86.6 \\
\hline Beefeater & Gin & Allied Domecq Spirits & 628.2 & $2,593.6$ \\
\hline Belvedere $^{\mathrm{a}}$ & Vodka & Millenium Import & 295.7 & $3,752.8$ \\
\hline Black Velvet & Whiskey & Constellation (Grand Metropolitan, -1997) & $1,829.6$ & 760.3 \\
\hline Bombay Original \& Sapphire & Gin & Bacardi USA (Grand Metropolitan, -1997) & 551.2 & $7,453.6$ \\
\hline Canadian Club & Whiskey & Allied Domecq Spirits & $1,486.9$ & 296.5 \\
\hline Canadian Mist & Whiskey & Brown-Forman & $2,533.5$ & $3,341.7$ \\
\hline Capital Morgan & Rum & Diageo (Seagram, -2001) & $2,660.5$ & $12,596.5$ \\
\hline Chivas Regal & Whiskey & Pernod Ricard (Seagram, -2001) & 515.8 & $7,090.2$ \\
\hline Chopin ${ }^{b}$ & Vodka & Millenium Import & 63.3 & $1,428.4$ \\
\hline Christian Brothers & Brandy and Cognac & Heaven Hill (Grand Metropolitan, -1997) & $1,182.4$ & 208.6 \\
\hline Courvoisier & Brandy and Cognac & Allied Domecq Spirits & 454.3 & $2,163.5$ \\
\hline Crown Royal & Whiskey & Diageo (Seagram, -2001) & $2,492.9$ & $15,041.9$ \\
\hline Cutty Sark & Whiskey & Skyy (Allied Domecq Spirits, -1997) & 293.6 & $1,306.2$ \\
\hline DeKuyper & Cordials and Liqueurs & Jim Beam & $2,442.5$ & $1,031.5$ \\
\hline Dewar's & Whiskey & Bacardi USA (Schieffelin \& Somerset, -1997) & $1,446.7$ & $8,192.0$ \\
\hline Di Saronno & Cordials and Liqueurs & Bacardi USA (Grand Metropolitan, -1997) & 284.9 & $3,768.6$ \\
\hline $\mathrm{E} \& \mathrm{~J}$ & Brandy and Cognac & E\&J Gallo & $2,089.5$ & 31.5 \\
\hline E \& J Cask \& Creamc & Cordials and Liqueurs & E\&J Gallo & 434.1 & 376.3 \\
\hline Early Times & Whiskey & Brown-Forman & 933.8 & 453.3 \\
\hline Evan Williams & Whiskey & Heaven Hill & 914.5 & $1,585.7$ \\
\hline Finlandia & Vodka & Brown-Forman (Grand Metropolitan, -1995) & 291.6 & $2,210.3$ \\
\hline
\end{tabular}




\section{Appendix Table 1 Continued.}

\begin{tabular}{|c|c|c|c|c|}
\hline Liquor Brand & Segment & Supplier(s) & $\begin{array}{l}\text { Mean 9-Liter } \\
\text { Case Sales }\end{array}$ & $\begin{array}{l}\text { Mean Advertising } \\
\text { Expenditures }\end{array}$ \\
\hline Fleischmann's Gin & Gin & Constellation (United Distillers, -1994) & 394.2 & 11.5 \\
\hline Fleischmann's Royal Vodka & Vodka & Constellation (United Distillers, -1994) & 689.0 & 59.5 \\
\hline Glenlivet, The & Whiskey & Pernod Ricard (Seagram, -2001) & 182.3 & $4,817.2$ \\
\hline Goldschlager & Cordials and Liqueurs & Diageo (Grand Metropolitan, -1997) & 242.7 & 304.8 \\
\hline Gordon's Gin & Gin & Diageo (United Distillers, -1997) & $1,134.6$ & 496.0 \\
\hline Grand Marnier & Cordials and Liqueurs & $\begin{array}{l}\text { Moet Hennessy (Schieffelin \& Somerset, -2003; } \\
\text { Grand Metropolitan, -1994) }\end{array}$ & 417.5 & $4,840.6$ \\
\hline Grey Goosed & Vodka & Bacardi USA (Sidney Frank, -2003) & 762.1 & $7,714.1$ \\
\hline Heaven Hill Bourbon & Whiskey & Heaven Hill & 276.4 & 41.5 \\
\hline Hennessy & Brandy and Cognac & Moet Hennessy (Schieffelin \& Somerset, -2003) & $1,340.6$ & $8,701.9$ \\
\hline Hiram Walker Cordials & Cordials and Liqueurs & Allied Domecq Spirits & $1,067.5$ & 16.0 \\
\hline Hpnotiqe & Cordials and Liqueurs & Heaven Hill & 620.0 & 739.4 \\
\hline $\mathrm{J} \& \mathrm{~B}$ & Whiskey & $\begin{array}{l}\text { Diageo (Schieffelin \& Somerset, -2003; Grand } \\
\text { Metropolitan, -1997) }\end{array}$ & 623.5 & $1,533.9$ \\
\hline Jack Daniel & Whiskey & Brown-Forman & $3,606.2$ & $14,930.0$ \\
\hline Jack Daniel's Country Cocktails & Prepared Cocktails & Brown-Forman & $1,099.4$ & $2,907.0$ \\
\hline Jagermeister & Cordials and Liqueurs & Sidney Frank & 736.8 & 63.3 \\
\hline Jim Beam & Whiskey & Jim Beam & $3,321.8$ & $10,030.1$ \\
\hline Johnnie Walker Black & Whiskey & Diageo (Schieffelin \& Somerset, -2003) & 548.5 & $3,327.5$ \\
\hline Johnnie Walker Red & Whiskey & Diageo (Schieffelin \& Somerset, -2003) & 798.6 & $1,372.4$ \\
\hline Jose Cuervo & Tequila & Diageo (Grand Metropolitan, -1997) & $2,947.7$ & $7,420.7$ \\
\hline Kahlua & Cordials and Liqueurs & Allied Domecq Spirits & $1,378.0$ & $5,815.8$ \\
\hline Kamora & Cordials and Liqueurs & Jim Beam & 215.5 & 103.4 \\
\hline Kessler & Whiskey & Jim Beam & 909.3 & 84.7 \\
\hline Korbal & Brandy and Cognac & Brown-Forman & 438.6 & 78.1 \\
\hline Lord Calvert & Whiskey & Jim Beam & 709.3 & 12.9 \\
\hline Majorska & Vodka & Star Industries & 244.5 & 30.0 \\
\hline
\end{tabular}


Appendix Table 1 Continued.

\begin{tabular}{|c|c|c|c|c|}
\hline Liquor Brand & Segment & Supplier(s) & $\begin{array}{l}\text { Mean 9-Liter } \\
\text { Case Sales }\end{array}$ & $\begin{array}{l}\text { Mean Advertising } \\
\text { Expenditures }\end{array}$ \\
\hline Maker's Mark & Whiskey & Allied Domecq Spirits & 320.9 & $2,082.2$ \\
\hline Malibu & Rum & $\begin{array}{l}\text { Allied Domecq Spirits (Diageo, -2001; Grand } \\
\text { Metropolitan, -1997) }\end{array}$ & 733.5 & $1,741.5$ \\
\hline Martell & Brandy and Cognac & Pernod Ricard (Seagram, -2001) & 230.3 & $1,318.7$ \\
\hline Old Forester & Whiskey & Brown-Forman & 169.6 & 297.7 \\
\hline Paul Masson Brandy & Brandy and Cognac & Constellation & 837.2 & $1,074.9$ \\
\hline Presidente & Brandy and Cognac & Allied Domecq Spirits & 227.9 & 101.7 \\
\hline Romana Sambuca Black/Caffe & Cordials and Liqueurs & Diageo (Grand Metropolitan, -1997) & 225.5 & 488.4 \\
\hline Ronrico & Rum & Jim Beam & 536.5 & 72.6 \\
\hline Rumple Minze & Cordials and Liqueurs & Diageo (Grand Metropolitan, -1997) & 236.0 & 62.1 \\
\hline Sauza & Tequila & Allied Domecq Spirits & 666.8 & $2,784.1$ \\
\hline Seagram's 7 Crown & Whiskey & Diageo (Seagram, -2001) & $2,748.5$ & $1,186.7$ \\
\hline Seagram's Gin & Gin & Pernod Ricard (Seagram, -2001) & $3,283.2$ & $3,585.8$ \\
\hline Seagram's Gin \& Juice & Prepared Cocktails & Pernod Ricard (Seagram, -2001) & 165.1 & 250.5 \\
\hline Seagram's V. O. & Whiskey & Diageo (Seagram, -2001) & $1,500.1$ & 527.6 \\
\hline Seagram's Vodkae & Vodka & Pernod Ricard & 550.0 & 230.3 \\
\hline Skyy & Vodka & Skyy Spirits & 989.9 & $4,754.6$ \\
\hline Smirnoff & Vodka & Diageo (Grand Metropolitan, -1997) & $6,353.5$ & $12,366.3$ \\
\hline Southern Comfort & Cordials and Liqueurs & Brown-Forman & $1,243.2$ & $5,032.6$ \\
\hline Stolichnaya & Vodka & $\begin{array}{l}\text { Allied Domecq Spirits (Diageo, -2000; Grand } \\
\text { Metropolitan, -1997) }\end{array}$ & $1,345.1$ & $6,334.7$ \\
\hline TGI Friday's & Prepared Cocktails & Diageo (Grand Metropolitan, -1997) & $1,016.0$ & 154.0 \\
\hline Tanqueray & Gin & Diageo (Schieffelin \& Somerset, -2003) & $1,380.9$ & $6,600.4$ \\
\hline Wild Turkey & Whiskey & Pernod Ricard (Grand Metropolitan, -1997) & 487.7 & $2,585.2$ \\
\hline Windsor & Whiskey & Jim Beam & $1,351.8$ & 118.2 \\
\hline
\end{tabular}

Note: a Introduced in 1996, first year in sample is 1998. ${ }^{\mathrm{b}}$ Introduced in 1997, first year in sample is $2001 .{ }^{\mathrm{c}}$ Introduced in 1998, first year in sample is 1998. ${ }^{\text {d }}$ Introduced in 1997, first year in sample is 1998. ${ }^{\mathrm{e}}$ Introduced in 2003, first year in sample is 2003. 